\title{
Effect of weld microstructure on brittle fracture initiation in the thermally- aged boiling water reactor pressure vessel head weld metal
}

\author{
Noora Hytönen ${ }^{1)}$, Zai-qing Que $e^{1)}$, Pentti Arffman ${ }^{1)}$, Jari Lydman ${ }^{1)}$, Pekka Nevasmaa ${ }^{1)}$, Ulla Ehrnstén ${ }^{1)}$, and \\ Pål Efsing ${ }^{2)}$ \\ 1) Nuclear Reactor Materials, VTT Technical Research Centre of Finland Ltd., Kivimiehentie 3, P.O. Box 1000, FI-02044 VTT, Finland \\ 2) Department of Solid Mechanics, Royal Institute of Technology (KTH), SE-100 44 Stockholm, Sweden \\ (Received: 9 September 2020; revised: 20 October 2020; accepted: 18 November 2020)
}

\begin{abstract}
Effects of the weld microstructure and inclusions on brittle fracture initiation are investigated in a thermally aged ferritic high-nickel weld of a reactor pressure vessel head from a decommissioned nuclear power plant. As-welded and reheated regions mainly consist of acicular and polygonal ferrite, respectively. Fractographic examination of Charpy V-notch impact toughness specimens reveals large inclusions $(0.5-2.5 \mu \mathrm{m})$ at the brittle fracture primary initiation sites. High impact energies were measured for the specimens in which brittle fracture was initiated from a small inclusion or an inclusion away from the V-notch. The density, geometry, and chemical composition of the primary initiation inclusions were investigated. A brittle fracture crack initiates as a microcrack either within the multiphase oxide inclusions or from the debonded interfaces between the uncracked inclusions and weld metal matrix. Primary fracture sites can be determined in all the specimens tested in the lower part of the transition curve at and below the 41-J reference impact toughness energy but not above the mentioned value because of the changes in the fracture mechanism and resulting changes in the fracture appearance.
\end{abstract}

Keywords: reactor pressure vessel; brittle fracture; weld microstructure; thermal aging

\section{Introduction}

Structural integrity of the reactor pressure vessel (RPV) in a nuclear power plant is of utmost importance. During operation, the RPV is subjected to thermal loading and neutron irradiation, which can cause embrittlement and shift the ductile-to-brittle transition temperature (DBTT) of ferritic steel weld with a body-centered cubic crystal structure toward high temperatures [1]. Embrittlement is monitored using surveillance programs, which state and predict the embrittlement and ensure safe margins toward brittle fracture. These programs use either Charpy V-notch (CVN) impact and/or fracture toughness test specimens. Welds are typically more critical than base materials in terms of irradiation-induced embrittlement. Embrittlement of RPV steels and weld metals is extensively studied [2-8], and numerous investigations are ongoing.

Understanding the microstructural factors affecting brittle fracture initiation and how they may be influenced by thermal aging and/or irradiation is important to achieve the improved mechanistic comprehension of brittle fracture and embrittlement. The first theories about the brittle fracture initiation mechanism were introduced by Griffith [9]. In this classical description of the problem, a microcrack is assumed to initiate within a brittle particle when the stress exceeds a critical value. The microcrack propagates from the broken particle and develops into a macrocrack. However, microcracks can also be initiated at the interface between secondary particles and matrixes because of debonding [10]. Nevertheless, stress concentration in a particle is always greater than that at the interface [10]. The weakest link model for crack initiation at a particle was introduced first by Weibull [11-12] and later modified by Beremin et al. [13]. The abovementioned models describe the relationship between a particle size and probability for brittle fracture initiation [2,14-17]. Bowen et al. [18] concluded that carbides in a martensitic base material are primary initiators of brittle fracture. Hein et al. [19] noted a difference between RPV base materials and weld metals, in which inclusions were the primary initiators. Investigations into thermally-aged weld metals and steels at high temperatures have concluded that thermal aging changes the initiation of brittle fracture from 
particles to intergranular (IG) fracture [20-21]. Thus, extensive data on the role of microstructure on brittle fracture initiation is needed and should be used in further developing brittle fracture models [20].

Weld metals contain secondary particles of different types and sizes. Nickel (Ni), manganese (Mn), and silicon (Si) form complex inclusions that promote the formation of acicular ferrite. Acicular ferrite is the desired weld microstructure resulting in good toughness properties [22-24]. However, RPV operating conditions are known to promote brittleness due to increased clustering and embrittlement during irradiation [3-4,25-26]. Thermal aging of a high-Ni-content weld metal in a pressurizer at $350^{\circ} \mathrm{C}$ for 27 years has been observed to cause an increase in the DBTT [3] and clustering [27] and the initiation of low toughness fracture as IG fracture. Single-phase inclusions such as simple oxides and sulfides $\left(\mathrm{Al}_{2} \mathrm{O}_{3}, \mathrm{MnO}\right.$, and $\left.\mathrm{MnS}\right)$ cannot nucleate acicular ferrite. Nucleation on an inert surface is a heterogeneous process in which interfacial energy is a major controlling factor [28]. Hence, complex multiphase inclusions are highly effective nucleation sites [24]. Furthermore, the mechanism for acicular ferrite nucleation is dependent on the surface area of the inclusions, and thus, intermediate-sized inclusions or small inclusions on a high density promote acicular ferrite nucleation effectively [29]. Oxide inclusions, treated as brittle particles that fulfill the Griffith criterion of brittle fracture initiation, may act brittle because of the intrinsic crystal structure or the preceding small defects within the inclusions that are likely to initiate cleavage fracture. For oxysulfides, which are highly ductile, matrix debonding can induce cracking within materials and cause further fracture. The characterization of inclusions of investigated weld metal is essential for understanding brittle fracture initiation mechanisms [30].

The investigated RPV weld metal is from a decommissioned boiling water reactor, which had been operated for 23 effective full power years at $288^{\circ} \mathrm{C}$. The investigated weld metal is high in $\mathrm{Ni}$ and $\mathrm{Mn}$. The same weld metal is used in several reactors, and it has been investigated earlier e.g., using surveillance materials [4,20,31-32]. The current investigation is part of larger programs, namely, BREDA and BRUTE. It involves mechanical testing and microstructural characterization on RPV head and beltline materials. The main objective of the project is to verify surveillance results by using RPV materials from a decommissioned nuclear power plant and to gain rich mechanistic insights. Meanwhile, the current study aims to broaden the understanding of the factors affecting brittle fracture by characterizing the weld metal of an RPV head removed from a decommissioned RPV subjected to thermal aging but not to irradiation. The characterization focuses on the microstructure, CVN brittle fracture initiation, and primary fracture inclusion initiators.

\section{Experimental}

The material investigated herein was from the decommissioned Barsebäck Unit 2 boiling water reactor. The reactor was in operation for 23 effective full power years at $288^{\circ} \mathrm{C}$. Cylinder-shaped trepans were drilled from the RPV head weld and used for mechanical tests and microstructural characterization. The investigated weld metal was manufactured using the submerged arc welding (SAW) method while the remaining $\sim 16 \mathrm{~mm}$ - of the $\sim 70$-mm-thick weld was made using manual metal arc (MMA) welding. The trepans were machined into smaller sections and plates, from which the investigated specimens were cut. The investigated filler materials, namely, Phoenix-Union S3NiMo in the SAW weld and Oerlicon Tenacito 65 in the MMA weld, were high in Ni and $\mathrm{Mn}$. The chemical composition of the weld based on optical emission spectrometry is presented in Table 1 . The yield strength and tensile strength are 520 and $610 \mathrm{MPa}$, respectively.

Table 1. Chemical composition of weld metal according to optical emission spectrometry

\begin{tabular}{ccccccccccccc}
\hline Weld & $\mathrm{C}$ & $\mathrm{Mn}$ & $\mathrm{Ni}$ & $\mathrm{Si}$ & $\mathrm{Mo}$ & $\mathrm{Cr}$ & $\mathrm{S}$ & $\mathrm{P}$ & $\mathrm{Cu}$ & $\mathrm{Al}$ & $\mathrm{Ti}$ & $\mathrm{Co}$ \\
\hline SAW weld & 0.057 & 1.43 & 1.48 & 0.15 & 0.41 & 0.03 & 0.007 & 0.008 & 0.060 & 0.024 & 0.003 & 0.020 \\
MMA weld & 0.037 & 1.38 & 1.22 & 0.25 & 0.37 & 0.03 & 0.007 & 0.007 & 0.004 & 0.002 & 0.004 & 0.018 \\
\hline
\end{tabular}

\subsection{Optical microscopy}

The weld solidification microstructure, heat-affected zone (HAZ), and base material were characterized using the Zeiss Axio Observer 7 inverted optical microscope to observe and distinguish the different phases and microstructural features. The metallography specimens were polished and etched with $3 \mathrm{vol} \%$ Nital solution $\left(\mathrm{HNO}_{3}+\right.$ ethanol). The multipass weld microstructure was examined through the wall thickness and involved samples from the inner wall side welded with the SAW method and the outer wall side welded with the MMA welding method (Fig. 1). Macro- and micro-hardness measurements $\left(\mathrm{HV}_{10}, \mathrm{HV}_{1}\right)$ were performed to establish the rela- tion between microstructure and hardness.

The location of the investigated microstructure, i.e., aswelded or reheated region, was determined from cross sections prepared as close as possible to the initiation site after the fractography.

\subsection{Inclusion analysis}

Using the Genesis Software, the density, geometry, and chemical composition of inclusions in the SAW weld microstructure was investigated through energy dispersive X-ray spectroscopy (EDS) with $10 \mathrm{keV}$ at a current density of $3 \mathrm{nA}$. An automated feature-sizing analysis was used for the size 

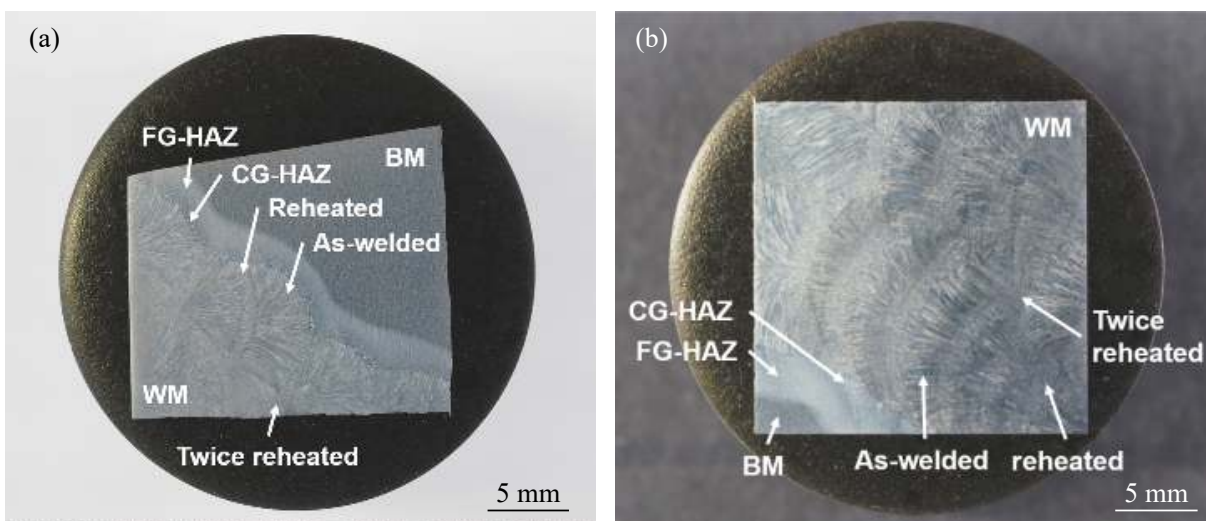

Fig. 1. Specimens for the characterization of investigated weld: (a) specimen from the inner wall side welded by the SAW method; (b) specimen from the outer wall side welded by the MMA welding method. Different metallurgical regions are indicated using arrows, i.e., base material (BM), weld metal (WM), fine-grained (FG), and coarse-grained (CG) HAZ.

distribution as the inclusions were recognized automatically through preset thresholds in the image brightness histogram. Statistical chemical analysis was performed using Genesis Chem, in which point analysis was automatically performed from the centroid of each recognized particle.

The inclusion analysis for the as-welded and reheated regions was conducted with an imaging field covering an area of $75 \mu \mathrm{m} \times 57 \mu \mathrm{m}$ on an image with a resolution of $2048 \mathrm{px}$, resulting in a pixel size of $35 \mathrm{~nm}$. As $2 \mathrm{px}$ is the minimum size for features to be recognized as an inclusion, a sufficiently identified minimum inclusion size is $70 \mathrm{~nm}$. In this work, 1339 inclusions (from eight fields) and 960 inclusions (from nine fields) were analyzed for the as-welded and reheated zones, respectively.

The analysis of the potential primary brittle fracture inclusions with large sizes $(>0.35 \mu \mathrm{m})$ was conducted with an imaging field covering an area of $217.4 \mu \mathrm{m} \times 169.8 \mu \mathrm{m}$ on an image with a resolution of $2048 \mathrm{px}$, resulting in a pixel size of $106 \mathrm{~nm}$. A total of 100 fields were examined, and 9398 inclusions were analyzed with a total scanned area of $3.69 \mathrm{~mm}^{2}$.

\subsection{Charpy V-notch impact toughness testing}

The CVN impact toughness specimens were tested according to the standard SFS-EN ISO-148-1:2016 [33]. The tests were performed using a Zwick RKP450 instrumented pendulum with automatic temperature control and feeding system. The pendulum was equipped with a 2-mm striker with a nominal impact energy of $300 \mathrm{~J}$. Instrumented strain gauges in the striker tip measured the impact force and was compared with deflection in terms of the pendulum angle. The frictional loss measured regularly for free swings and estimated individually for each test consistently yielded a loss of $1.0-1.3 \mathrm{~J}$.

The standard specimens measured $55 \mathrm{~mm} \times 10 \mathrm{~mm} \times$ $10 \mathrm{~mm}$. The specimens for the CVN impact toughness test were cut at one-quarter from the inner surface, with the notch in the middle of the weld. The orientation of the CVN speci- mens was T-S, which is different from the recommended T-L orientation [34]. In the weld structure, L is the longitudinal direction of welding around the RPV while $\mathrm{S}$ is the building direction of the multipass weld.

The transition curve was formed by the transition temperature reference points determined at impact toughness energies of 28,41 , and $68 \mathrm{~J}$ on a tanh curve with a low shelf impact energy conservatively set to $2 \mathrm{~J}$ and an upper shelf estimated as the mean of completely ductile tests. The first test was performed at ambient temperature, and the subsequent temperatures were selected according to the development of the transition curve.

\subsection{Fractographic examination}

The fracture surfaces of nine CVN specimens with brittlelike fracture appearance from the lower shelf of the transition curve were investigated using the scanning electron microscope Zeiss Crossbeam 540. The characterization focused on the primary fracture initiation sites and their surrounding areas. The distance of the initiation location was measured from the V-notch to further evaluate the triaxial stress state.

The aim of the analysis was to identify the features and local chemical composition differences at or adjacent to the fracture initiation sites that exerted an impact on fracture behavior. The semiquantitative chemical compositions of the primary fracture area and initiation site were obtained using EDAX Octane Plus EDS. The topography of the fracture surface inevitably affects EDS mapping. Herein, the semiquantitative results revealed the different compositions of the particles relative to the surrounding weld and could thus be compared with the results of the inclusion analysis.

\section{Results}

\subsection{Microstructure}

The multipass weld is built by weld beads with average heights of 4 and $3 \mathrm{~mm}$ in the weld parts from SAW and 
MMA welding, respectively, with reheated regions measuring approximately $1 \mathrm{~mm}$ in height. The HAZ is uniform throughout the weld and can be divided into fine-grained (FG) and coarse-grained (CG) regions. The weld microstructure is shown in Fig. 2. The epitaxial grain growth begins from the CG-HAZ across the fusion line in the preferred crystallographic direction $<100>$ and inwards to the weld (Fig. 2(a)). The acicular ferrite forms into the parent austenite grains during the solidification of the weld bead. Most of the dendritic weld beads consist of intragranularly nucleated acicular ferrite with small fractions of grain boundary ferrite between the dendrites (Fig. 2(b)). Acicular ferrite has a typical fine basket weave structure and differs significantly from the pre-eutectoid grain boundary ferrite observed as light- colored elongated areas.

In multipass welding, the heat input from consecutive layers affects the microstructure of the as-welded grain structure by refining the dendritic grains through recrystallization. The reheated microstructure aligns the fan-shaped weld bead of the new weld layer. The reheated microstructure is shown in Fig. 2(c), where the microstructure mainly consists of polygonal ferrite. Polygonal ferrite appears as light-colored areas in the microstructure without a particular shape. The SAW and MMA welds show no significant differences in microstructure. Only a few large TiC particles are observed in the MMA weld, and they may be due to the impurities from the welding process. In the MMA HAZ region, a few grains of martensite are observed.
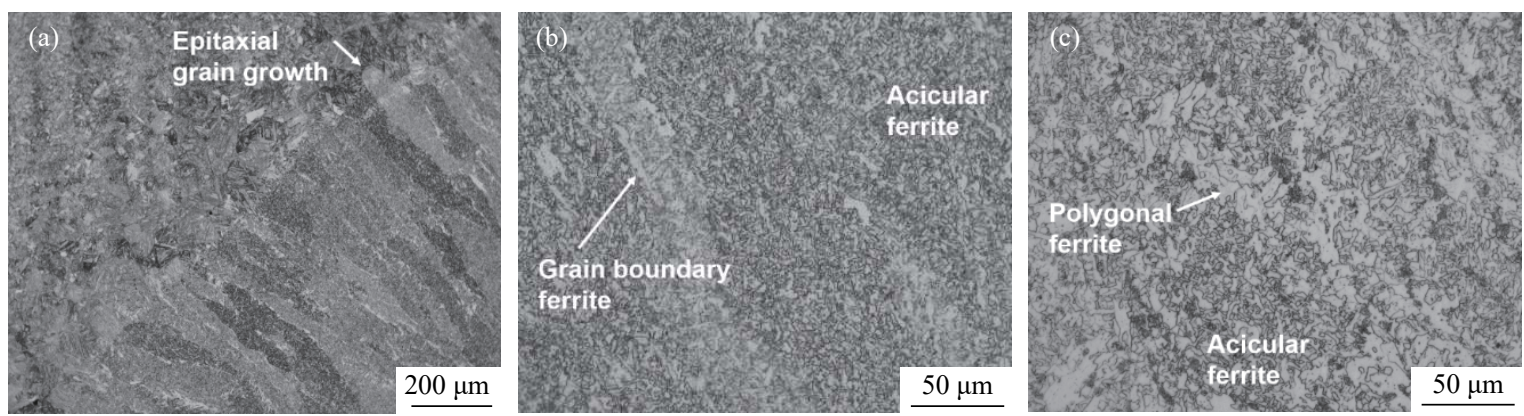

Fig. 2. Regions of weld microstructure: (a) epitaxial growth over the fusion boundary from the parent grain in the CG-HAZ toward the weld solidification bead; (b) weld bead microstructure with acicular ferrite and grain boundary ferrite; (c) reheated microstructure containing mainly polygonal ferrite.

The Vickers hardness results measured on 98.1-N load across the weld build-up thickness from the inner wall to the outer wall are shown in Fig. 3, which highlights an average hardness of $\mathrm{HV}_{10} 210 \pm 5$. The lower hardness of up to 12 $\mathrm{mm}$ from the inner wall is due to the thermal effect from the

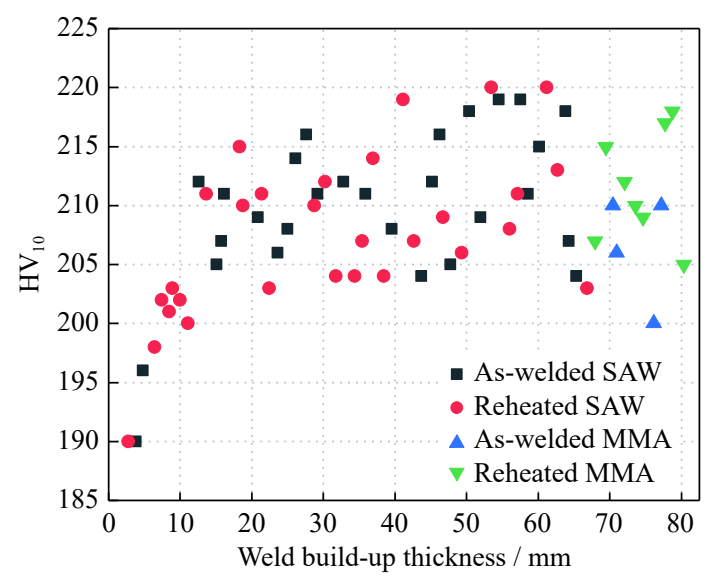

Fig. 3. $\mathrm{HV}_{10}$ results based on wall thickness. The results are divided into as-welded and reheated regions with SAW or MMA welding methods; the build-up thickness is measured from the inner wall to outer wall. cladding process. The plots do not indicate differences between the two welding methods. $\mathrm{HV}_{1}$ is measured over the fusion line, indicating the highest hardness peak at the CGHAZ region. According to the hardness measurements, i.e., $\mathrm{HV}_{10}$ and $\mathrm{HV}_{1}$, no large areas show a hardened microstructure because the size of the martensitic grains is smaller than that of the indents.

\subsection{Inclusion analysis}

The secondary particles in the as-welded and reheated microstructural regions are investigated separately on the metallography specimens. The analyses include the inclusion distribution and geometry analysis (size, aspect ratio, area, and diameter). Table 2 presents the average diameter and density of the inclusions for the as-welded and reheated regions. With regard to the inclusion density, the as-welded region has approximately 1.5 times more inclusions than the reheated

Table 2. Average inclusion size and density in as-welded and reheated microstructures

\begin{tabular}{ccc}
\hline Region & Average diameter $/ \mu \mathrm{m}$ & Density $/ \mathrm{mm}^{-2}$ \\
\hline As-welded & 0.288 & 40805 \\
Reheated & 0.325 & 25995 \\
\hline
\end{tabular}


region. The average size is slightly smaller in the as-welded region $(0.288 \mu \mathrm{m})$ than in the reheated microstructure $(0.325$ $\mu \mathrm{m})$. Statistically, the most probable inclusion sizes are 0.23 $\mu \mathrm{m}$ in the as-welded region and $0.27 \mu \mathrm{m}$ in the reheated region (Fig. 4(a)). The aspect ratio of all the measured inclusions is close to 1 , indicating that the inclusions are mostly spherical as expected.

The analysis of the potential primary brittle fracture initiators with large sizes $(0.35-5 \mu \mathrm{m})$ reveals 9398 inclusions in a total scanned area of $3.69 \mathrm{~mm}^{2}$, resulting in an inclusion

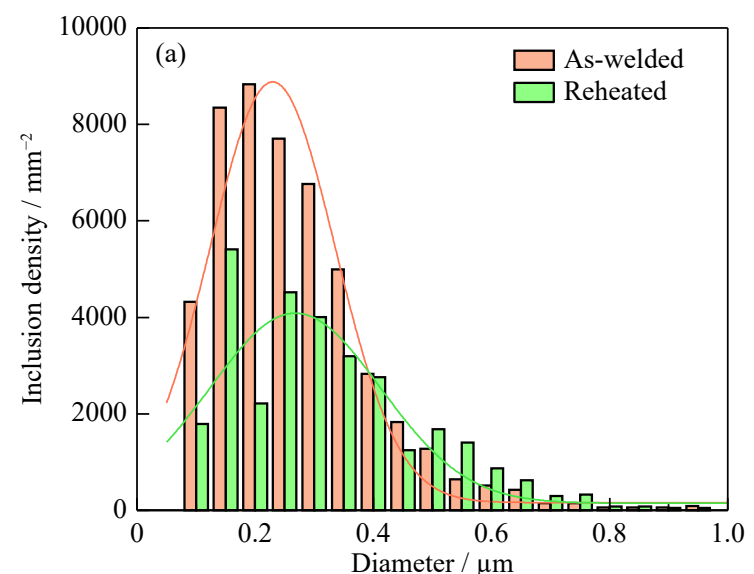

density of $2546 \mathrm{~mm}^{-2}$. The inclusion density with the inclusion diameters of the potential primary brittle fracture inclusions is shown in Fig. 4(b). The smallest and biggest inclusions recorded herein have diameters of 0.32 and $4.69 \mu \mathrm{m}$, respectively. However, only three inclusions have diameters larger than $1.8 \mu \mathrm{m}$ in the scanned area. The inclusion density of the potential primary brittle fracture inclusions is more reasonable than the average results from the as-welded and reheated regions shown in Fig. 4(a) (the accumulated density of particles with diameters above $0.4 \mu \mathrm{m}$ ).

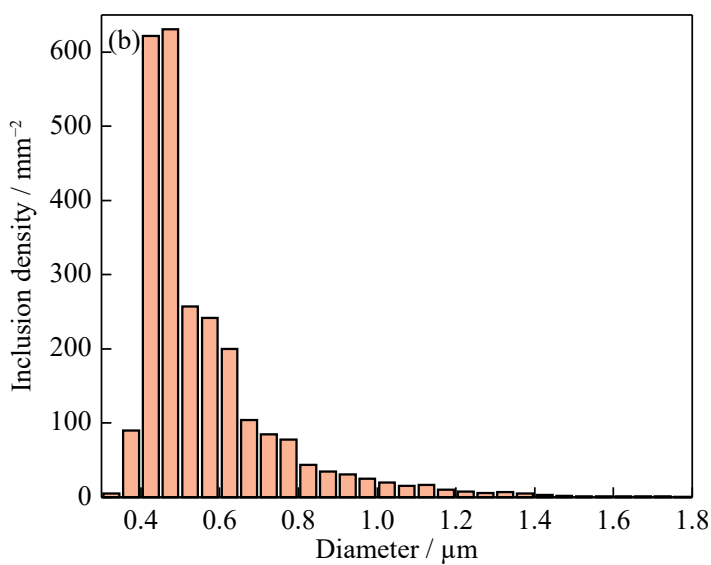

Fig. 4. (a) Inclusion density with inclusion diameters in the as-welded and reheated regions following the log-normal fitting; (b) inclusion density with inclusion diameters for the potential primary brittle fracture initiators in weld metal.

The chemical analyses are conducted with the electron beam set at $10 \mathrm{keV}$, which produces an interaction volume with a diameter of about $400 \mathrm{~nm}$ on Fe (based on a Monte Carlo simulation and comparable to the detected inclusion size). Limited background signals from the matrix materials are collected, and they lead to a reasonably precise chemical composition analysis. The average chemical composition of the 9398 large inclusions in weld metal is listed in Table 3. The main elements detected are $\mathrm{Fe}, \mathrm{Mn}, \mathrm{Al}, \mathrm{Si}, \mathrm{O}$, and $\mathrm{S}$. In Fig. 5, the main elements are given in ternary diagrams of $\mathrm{Mn}-\mathrm{Si}-\mathrm{Al}$ and $\mathrm{S}-\mathrm{Fe}-\mathrm{O}$. The element content of the inclusion is higher when the circle is closer to the corner, and the size of the circle corresponds to the size of the inclusion. The color of the circle is a mix of RGB colors and varies with the
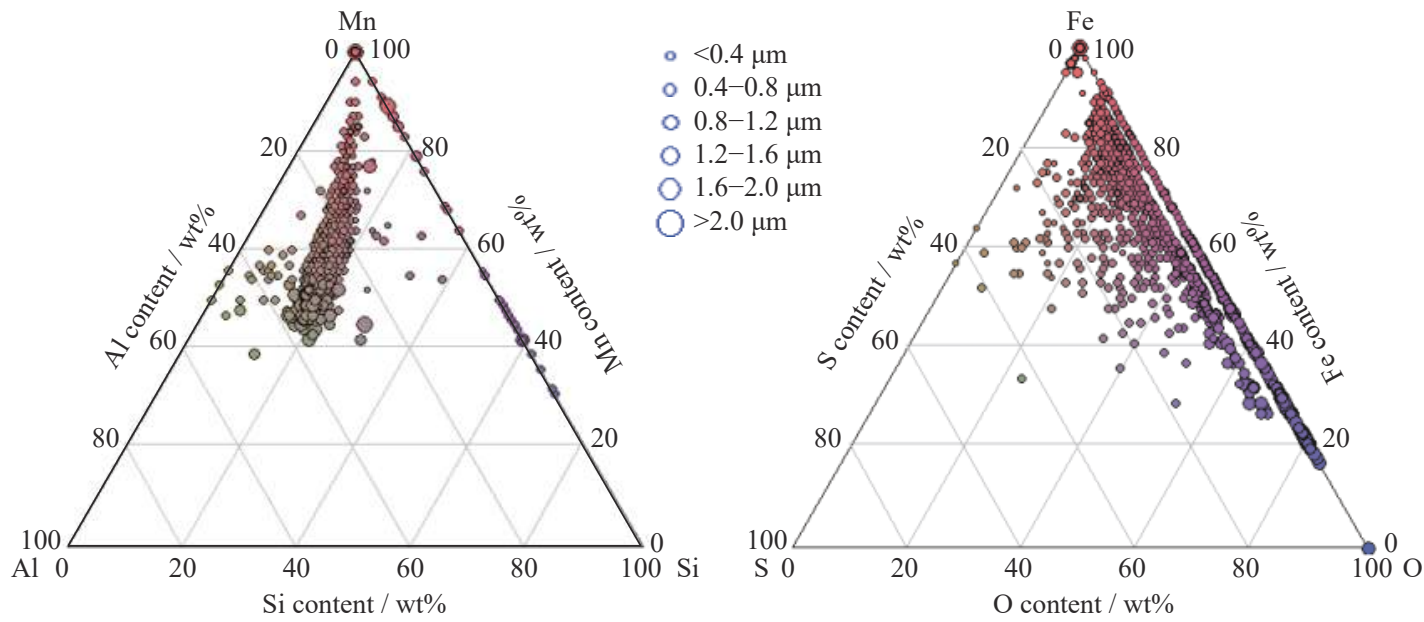

Fig. 5. Ternary diagrams of major elements ( $\mathrm{Mn}-\mathrm{Al}-\mathrm{Si}$ and $\mathrm{S}-\mathrm{Fe}-\mathrm{O})$ and size correlations for the potential primary brittle fracture inclusions - the analysis is conducted using large inclusion particles; the size scale is presented in the middle. 
concentration of the corner elements. The inclusions in the weld metal are mainly $\mathrm{Fe}-\mathrm{Mn}-\mathrm{Al}$-containing (S)O complex compounds, which consist of mixing oxides (Al, $\mathrm{Si}, \mathrm{Fe}$, and $\mathrm{Mn}$ oxides) and sulfides ( $\mathrm{Mn}$ and Fe sulfides). The size of the inclusions increases with the $\mathrm{O}$ and/or Fe content. A limited amount of pure oxides or sulfides exist, but the amount of pure oxides is at least a magnitude higher than that of the pure sulfide inclusions.

Table 3. Average chemical composition of potential primary brittle fracture inclusions with large sizes $(0.35-5 \mu \mathrm{m})$ in weld metals

\begin{tabular}{cccccc}
\hline $\mathrm{Fe}$ & $\mathrm{Mn}$ & $\mathrm{Al}$ & $\mathrm{Si}$ & $\mathrm{O}$ & $\mathrm{S}$ \\
\hline 38.02 & 25.75 & 11.93 & 7.26 & 15.55 & 1.49 \\
\hline
\end{tabular}

\subsection{Fractography}

The transition curve in the project is formed by $23 \mathrm{CVN}$ specimens from a one-quarter depth of the trepans. Among the CVN specimens, nine from the lower shelf are included in the fractographic investigation. The fractography results indicate that the 41-J reference point seems to be the location where the brittle fracture mechanism changes as the specimens tested above that impact energy do not present a determinable primary fracture site, whereas all the specimens tested at and below $41 \mathrm{~J}$ reflected such sites. Fig. 6 shows the full transition curve obtained in the testing. The investigated brittle specimens are from the lower part of the transition curve indicated in the figure.

The reference transition temperatures obtained in the $\mathrm{CVN}$ impact toughness testing are $T_{28 \mathrm{~J}}=-85^{\circ} \mathrm{C}, T_{41 \mathrm{~J}}=-75^{\circ} \mathrm{C}$, and $T_{68 \mathrm{~J}}=-60^{\circ} \mathrm{C}$, with the uncertainty estimated to be $\pm 5^{\circ} \mathrm{C}$. These values are similar to those of the non-aged reference material, thus indicating the negligible thermal embrittlement effect. The specimens included in the fractographic investigations are those tested below the transition temperature of $T_{41 \mathrm{~J}}=-75^{\circ} \mathrm{C}[35]$.

In the fracture surface characterization, the brittle fracture initiated in all specimens by transgranular fracture and an inclusion is found at the initiation site in each specimen. An example of a brittle fracture surface is shown in Fig. 7(a), in which the initiation site is marked with a red square. The cleavage fracture can be determined according to the characteristic river patterns. In the fractographic examination, both mating fracture surfaces are investigated as the inclusion or part of it may remain on the halves. Fig. 7(b) shows the magnified primary initiation site showing an inclusion. In most of the investigated fracture surfaces, relatively large uncracked inclusions measuring 1.5-2.5 $\mu \mathrm{m}$ exist at the initiation site.

Interdendritic (ID)-like and IG-like fracture areas as the secondary fracture mode in addition to cleavage fracture are observed in some of the as-welded and reheated microstructures, respectively. The ID-like fracture surface shown in Fig. 8 has presumably propagated along the grain boundary ferrite. This phenomenon has also been observed in the reference state, i.e., in the non-aged state of the same material. The fracture is not considered to be brittle as small dimples and flakes are observed at the ID/IG-like areas. However, the topography imitates the underlying microstructure in these areas. All initiation sites are located in the as-welded microstructure; they are not found in the reheated microstructure.

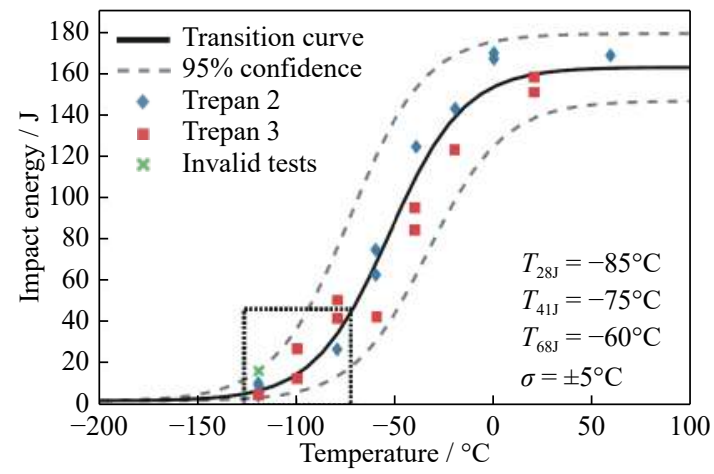

Fig. 6. Transition curve of Charpy V-notch impact toughness specimens. The investigated specimens with brittle fracture are inside the square.
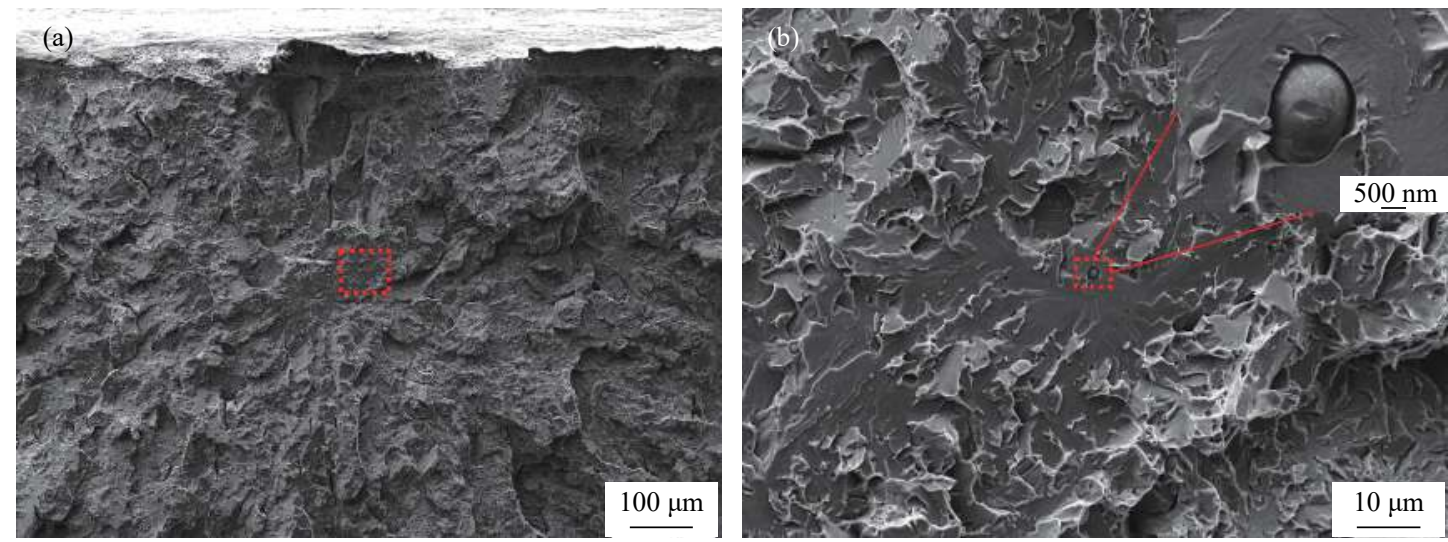

Fig. 7. Brittle cleavage fracture surface and an inclusion at the primary initiation site: (a) brittle cleavage fracture surface; (b) an inclusion at the primary initiation site. 

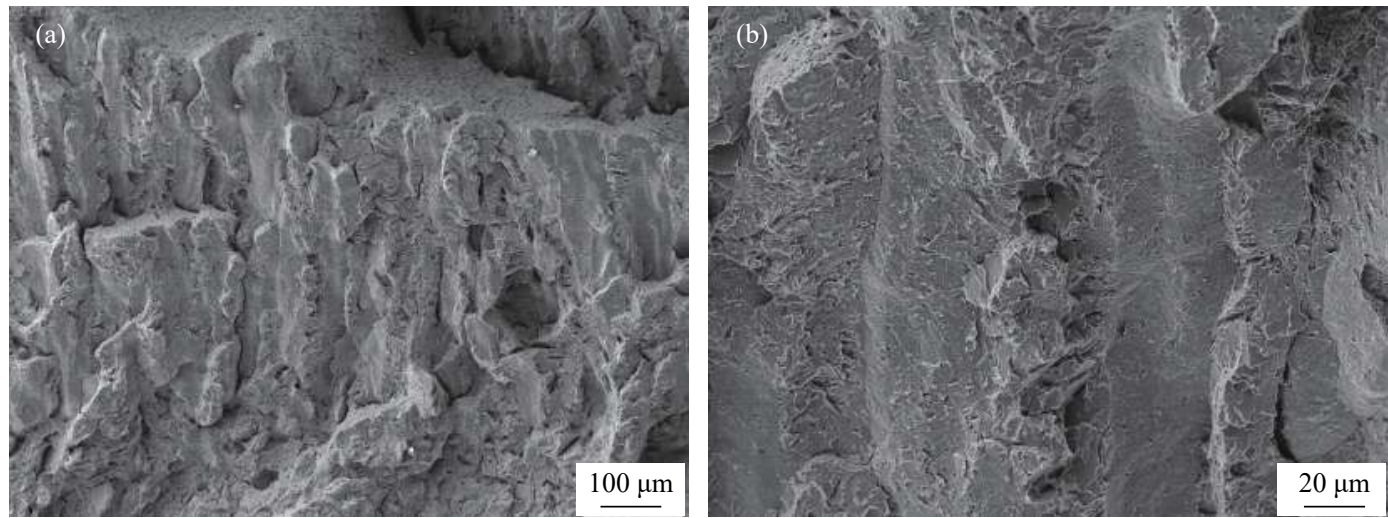

Fig. 8. (a) Interdendritic-like fracture in the as-welded region and (b) its higher magnification image. The fracture surface is not fully brittle.

This result is evidently due to the location of the notch in the weld bead.

\section{Discussion}

The presence of inclusions exerts an effect on brittle cleavage crack initiation [29]. Weld metals are composed of numerous and rather evenly distributed granular inclusions and are thus different from the base materials, in which the inclusions are typically large and sparsely distributed. The probability of an inclusion with suitable size for brittle fracture initiation is thus much higher in weld metals than in base materials, in which carbides become the weakest link [18]. The weld bead microstructure mainly contains acicular ferrite and polygonal ferrite, with the former having greater toughness properties. During solidification, the grain boundary ferrite nucleates first at the austenite grain boundaries while the acicular ferrite nucleates at the surface of the nonmetallic inclusions [36]. Widmanstätten ferrite may form at the parent austenite grain boundaries in competition with acicular ferrite. Alloying elements, such as Mn, promote the

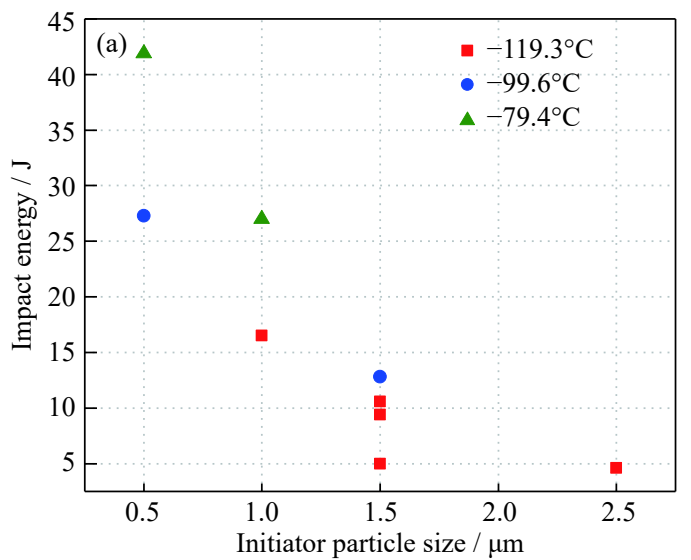

growth of acicular ferrite over the grain boundary phases [23]. No significant amount of Widmanstätten ferrite with lath structure was observed because of sufficient alloying and welding parameters. All initiation sites in the investigated specimens with brittle fractures are located in the as-welded microstructure. The large number of inclusions with large sizes $(0.5-2.5 \mu \mathrm{m})$ in the reheated region are shown in Fig. 4(b), and the large particles are normally predicted to be the brittle fracture initiators. However, the as-welded region with a dendritic microstructure can increase the probability of brittle fracture initiation relative to the reheated region with a granular microstructure and short crack paths. Further investigations are required to verify the superiority of the influence of the dendritic as-welded microstructure and large multiphase inclusions on brittle fracture initiation.

The correlation between the primary initiation particle parameters, namely, size and location, and the CVN impact energy of less than $41 \mathrm{~J}$ is grouped by testing temperature and plotted in Fig. 9. The specimens with large initiator particles result in relatively low-value impact toughness energies when tested at the same temperature (Fig. 9(a)). The large

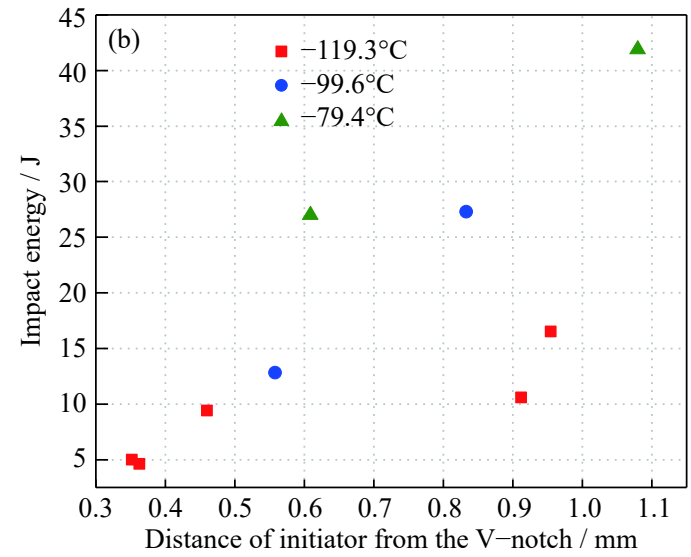

Fig. 9. Relation between primary initiation particle size $(\mu \mathrm{m})(\mathrm{a})$ and distance of the initiator from the V-notch (mm) (b) with impact energy. The specimens tested in the lower part of the transition curve show a trend as the weakest location in the process zone of the testing temperature breaks first. 
particle size $(1.5-2.5 \mu \mathrm{m})$ is correlated with the impact toughness energy below $15 \mathrm{~J}$. For large particles, the required applied stress to separate the interfaces is relatively low because the energy release rate increases with the particle size for the same applied stress [28]. The preceding plastic deformation and ductile region before the brittle fracture region in the CVN specimens are small at low values of impact energies. Therefore, the primary initiation site is also closer to the V-notch at a low impact toughness energy (Fig. 9(b)). The inclusion density and size distribution in the studied material show that the brittle fracture tends to initiate from the largest particle in the effective process zone acting as the weakest location and thus fulfills the weakest link theory. Nevertheless, a CVN specimen tested at $-59.8^{\circ} \mathrm{C}$ with an impact toughness energy of $62.9 \mathrm{~J}$ from the transition region of the DBTT curve has multiple initiation sites, with the primary initiation site being undetectable, in the relative adjacency of the V-notch. Additionally, the initiation particle parameters with impact energy do not fit the current trend, thereby demonstrating that the correlation is only fulfilled with the specimens tested below $41 \mathrm{~J}$ in the lower part of the transition curve.

Particle interface debonding is observed in the specimens in the lower part of the transition curve, where the plastic flow is limited. In Fig. 7(b), a debonded inclusion is shown at a cleavage fracture initiation site. Debonding is normally associated with void nucleation during plastic deformation when a second-phase particle remains more or less intact. The plastic strain breaks the interatomic bonding between the matrix and the particle instead of breaking the inclusion. The large inclusions increase the local inhomogeneity, which then promotes debonding. The interface debonding may initiate a microcrack in the surrounding brittle material and propagate as a macroscale cleavage fracture at low temperatures. Depending on the particle size, temperature, and chemical composition of the inclusion and the stress state, the microcrack initiates inside the inclusion or at the interface between the inclusion and the weld metal matrix [1,8-9,17,30,37-38]. Hence, multiple active mechanisms are needed to explain the behavior for aged materials because the traditional methodology, i.e., Griffith's theory with failure of an inclusion, is not enough without parallel mechanisms, such as the debonding of particles and/or grain boundary. In the model developed by Boåsen [20], debonding resulting from thermal aging is observed under high temperatures. The debonding may also be due to the segregation of impurities on the particle surfaces and reduction of the interface adhesion, because the effect of thermal embrittlement was not observed in the impact toughness of the investigated weld material. The chemical composition inhomogeneity and weak bonding at the interfaces are the probable causes of debonding on which thermal aging may have an effect. In addition to particle debonding, ID- and IG-like failures are observed. These phenomena are related as they result from the breaking of interfaces. As the low-temperature toughness properties increase, the relatively high-Ni-content $(1.4 w t \%-2.5 w t \%)$ in the weld metal increases the amount of grain boundary impurity segregation, which then seems to promote the ID/IG-like fracture mode $[3,14]$. Moreover, similar but brittle fracture areas are detected in the specimens with thermal aging-induced embrittlement, and the amount of ID/IG fracture is associated with the extent of DBTT shift [3]. The ID/IG fracture areas of brittle RPV welds are related to solute segregation, most commonly phosphorus [21,25,39].

According to the semiquantitative EDS analysis of the primary initiation sites, the particles at the crack initiation sites are mostly multiphase oxides. The main detected elements are $\mathrm{Mn}, \mathrm{Si}$, and $\mathrm{Al}$, all of which are alloying elements in the ferritic weld metal [24]. The multiphase oxide inclusions fulfill the Griffith criterion of brittle fracture initiation. The particle may be brittle because of the intrinsic crystal structure or the preceding small defects within the inclusion. Therefore, the inclusion is likely to crack in the presence of plastic strain and further initiate a cleavage fracture. In the case of other ductile oxy-sulfides, debonding at the interfaces between uncracked inclusions and weld metal matrixes can induce further brittle fracture. Debonding can be regarded as a result of mild thermal aging, which is too minimal to affect mechanical properties but is strong enough to cause debonding rather than particle cracking at the brittle fracture initiation site. The effect of thermal aging below $300^{\circ} \mathrm{C}$ on debonding that causes microcracking still requires further studies.

\section{Conclusions}

A thermally-aged high Ni low-alloyed weld metal from a decommissioned boiling water reactor RPV head was investigated. Thermal aging did not change the impact toughness of the weld metal. The microstructure characterization, inclusion analysis, and fractographic examination revealed the effects of the microstructure and secondary particles on the brittle fracture initiation. The main findings are as follows.

(1) The as-welded microstructure consisted mainly of acicular ferrite. The reheated microstructure consisted mainly of polygonal ferrite. Small fractions of grain boundary ferrite were observed. The amount of grain boundary ferrite was associated with the observed IG- and ID-like fracture surfaces.

(2) The inclusion density in the as-welded region was approximately 1.5 times higher than that in the reheated region. The inclusions were mainly $\mathrm{Fe}-\mathrm{Mn}-\mathrm{Al}$-containing (S)O complex compounds. All initiation sites in the investigated specimens with brittle fracture were located in the as-welded microstructure.

(3) Brittle fracture primarily initiated from inclusions with large sizes $(0.5-2.5 \mu \mathrm{m})$ in all the CVN specimens tested at 
the lower part of the transition curve. The cleavage fracture was initiated either within the brittle multiphase oxide inclusions or from the debonded interfaces between the uncracked inclusion and the weld metal matrix.

(4) The trend between particle size and location with impact energy was obtained. A low-impact energy was associated with the primary initiation site being closer to the Vnotch and a large initiator particle size.

(5) The primary fracture sites can be determined in all the specimens tested in the lower part of the transition curve at and below the 41-J reference impact toughness energy but not above this point because of the changes in the fracture mechanism and the resulting changes in fracture appearance.

\section{Acknowledgments}

The authors gratefully acknowledge the BREDA program (Barsebäck Research and Development Arena) for providing the research material and the SAFIR2022 BRUTE project (Barsebäck RPV material used for true evaluation of embrittlement) for funding the study. The contributions and discussions with M. Boåsen from KTH, S. Lindqvist from VTT, and I. Virkkunen from Aalto University are acknowledged as well.

Open Access funding provided by VTT Technical Research Centre of Finland

Open Access This article is licensed under a Creative Commons Attribution 4.0 International License, which permits use, sharing, adaptation, distribution and reproduction in any medium or format, as long as you give appropriate credit to the original author(s) and the source, provide a link to the Creative Commons licence, and indicate if changes were made. The images or other third party material in this article are included in the article's Creative Commons licence, unless indicated otherwise in a credit line to the material. If material is not included in the article's Creative Commons licence and your intended use is not permitted by statutory regulation or exceeds the permitted use, you will need to obtain permission directly from the copyright holder. To view a copy of this licence, visit http://creativecommons.org/licenses/by/4.0/.

\section{References}

[1] P. Haušild, C. Berdin, and P. Bompard, Prediction of cleavage fracture for a low-alloy steel in the ductile-to-brittle transition temperature range, Mater. Sci. Eng. A, 391(2005), No. 1-2, p. 188.

[2] A.H. Cottrell, Theory of brittle facture in steel and similar metals, Trans. Metall. Soc. AIME, 212(1958), p. 192.

[3] P. Joly, L. Sun, P. Efsing, J.P. Massoud, F. Somville, R. Gerard, Y.H. An, and J. Bailey, Characterization of in-service thermal ageing effects in base materials and welds of the pressure vessel of a decommissioned PWR pressurizer, after 27 years of operation, [in] 19th International Conference on Environmental
Degradation of Materials in Nuclear Power Systems-Water Reactors 2019, Boston, 2019, p. 392.

[4] K. Lindgren, M. Boåsen, K. Stiller, P. Efsing, and M. Thuvander, Evolution of precipitation in reactor pressure vessel steel welds under neutron irradiation, J. Nucl. Mater., 488(2017), p. 222.

[5] Y.A. Nikolaev, A.V. Nikolaeva, A.M. Kryukov, V.I. Levit, and Y.N. Korolyov, Radiation embrittlement and thermal annealing behavior of $\mathrm{Cr}-\mathrm{Ni}-\mathrm{Mo}$ reactor pressure vessel materials, $J$. Nucl. Mater., 226(1995), No. 1-2, p. 144.

[6] G.R. Odette and R.K. Nanstad, Predictive reactor pressure vessel steel irradiation embrittlement models: Issues and opportunities, JOM, 61(2009), No. 7, p. 17.

[7] R.S. Xing, D.J. Yu, G.F. Xie, Z.H. Yang, X.X. Wang, and X. Chen, Effect of thermal ageing on mechanical properties of a bainitic forging steels for reactor pressure vessel, Mater. Sci. Eng. A, 720(2018), p. 169.

[8] K. Wallin, M. Yamamoto, and U. Ehrnstén, Location of initiation sites in fracture toughness testing specimens: The effect of size and side grooves, [in] Proceedings of the ASME 2016 Pressure Vessels and Piping Conference, Volume 1B: Codes and Standards, Vancouver, 2016, art. No. V01BT01A011.

[9] A.A. Griffith, The phenomena of rupture and flow in solids, Philos. Trans. R. Soc. London, 221(1921), p. 163.

[10] A. Pineau, A.A. Benzerga, and T. Pardoen, Failure of metals I: Brittle and ductile fracture, Acta Mater., 107(2016), p. 424.

[11] W. Weibull, A statistical theory of the strength of materials, [in] Generalstabens Litografiska Anstalts Förlag, Stockholm, 1939.

[12] W. Weibull, A statistical distribution function of wide applicability, J. Appl. Mech., 18(1951), p. 293.

[13] F.M. Beremin, A. Pineau, F. Mudry, J.C. Devaux, Y. D'Escatha, and P. Ledermann, A local criterion for cleavage fracture of a nuclear pressure vessel steel, Metall. Trans. A, 14(1983), p. 2277.

[14] C.L. Briant and S.K. Banerji, Intergranular failure in steel: The role of grain-boundary composition, Int. Met. Rev., 23(1978), No. 1, p. 164.

[15] R.W. Hertzberg, R.P. Vinci, and J.L. Hertzberg, Deformation and Fracture Mechanics of Engineering Materials, 5th ed., John Wiley \& Sons, Chichester, 2013. p. 299.

[16] J.D. Landes and D.H. Shaffer, Statistical characterization of fracture in the transition region, [in] P. Paris ed., Fracture Mechanics, ASTM International, West Conshohocken, 1980. p. 368.

[17] K. Wallin, Fracture Toughness of Engineering Materials: Estimation and Application, FESI Publishing, 2011.

[18] P. Bowen, S.G. Druce, and J.F. Knott, Effects of microstructure on cleavage fracture in pressure vessel steel, Acta Metall., 34(1986), No. 6, p. 1121.

[19] H. Hein, J. Kobiela, M. Brumovsky, C. Huotilainen, J. Lydman, B. Marini, B. Radiguet, O. Startsev, M. Serrano Garcia, R. Hernandez Pascual, F. Roeder, and H.W. Viehrig, Addressing of specific uncertainties in determination of RPV fracture toughness in the SOTERIA project, [in] Fontevraud 9-Contribution of Materials Investigations and Operating Experience to Light Water NPPs' Safety, Performance and Reliability, Avignon, 2018.

[20] M. Boåsen, Modeling of Structural Integrity of Aged Low Alloy Steels Using Non-Local Mechanics, [Dissertation], KTH Royal Institute of Technology, Stockholm, Sweden, 2020.

[21] C.A. Hippsley and S.G. Druce, The influence of phosphorus segregation to particle/matrix interfaces on ductile fracture in a high strength steel, Acta Metall., 31(1983), No. 11, p. 1861. 
[22] H. Bhadeshia and R. Honeycombe, Steels: Microstructure and Properties, 4th ed. Elsevier Ltd., Cambridge, 2017.

[23] G.M. Evans, Effect of manganese on the microstructure and properties of all-weld-metal deposits, Welding Res. Suppl., 59(1980), No. 3, p. 67.

[24] J.H. Shim, Y.J. Oh, J.Y. Suh, Y.W. Cho, J.D. Shim, J.S. Byun, and D.N. Lee, Ferrite nucleation potency of non-metallic inclusions in medium carbon steels, Acta Mater., 49(2001), No. 12, p. 2115.

[25] B.A. Gurovich, E.A. Kulehsova, Y.I. Shtrombakh, O.O. Zabusov, and E.A. Krasikov, Intergranular and intragranular phosphorus segregation in russian pressure vessel steels due to neutron irradiation, J. Nucl. Mater., 279(2000), No. 2-3, p. 259.

[26] D.J. Sprouster, J. Sinsheimer, E. Dooryhee, S.K. Ghose, P. Wells, T. Stan, N. Almirall, G.R. Odette, and L.E. Ecker, Structural characterization of nanoscale intermetallic precipitates in highly neutron irradiated reactor pressure vessel steels, Scripta Mater., 113(2016), p. 18.

[27] K. Lindgren, M. Boåsen, K. Stiller, P. Efsing, and M. Thuvander, Cluster formation in in-service thermally aged pressurizer welds, J. Nucl. Mater., 504(2018), p. 23.

[28] J.S. Byun, J.H. Shim, Y.W. Cho, and D.N. Lee, Non-metallic inclusion and intragranular nucleation of ferrite in Ti-killed C-Mn steel, Acta Mater., 51(2003), No. 6, p. 1593.

[29] D.S. Sarma, A.V. Karasev, and P.G. Jönsson, On the role of non-metallic incluisons in the nucleation of acicular ferrite in steels, ISIJ Int., 49(2009), No. 7, p. 1063.

[30] U. Zerbst, R.A. Ainsworth, H.T. Beier, H.T. Pisarski, Z.L. Zhang, K. Nikbin, T. Nitschke-Pagel, S. Münstermann, P. Kucharczyk, and D. Klingbeil, Review on fracture and crack propagation in weldments-A fracture mechanics perspective, Eng. Fract. Mech., 132(2014), p. 200.

[31] M. Boåsen, K. Lindgren, J. Rouden, M. Öberg, J. Faleskog, M.
Thuvander, and P. Efsing, Thermal ageing of low alloy steel weldments from a Swedish nuclear power plant - A study of mechanical properties, [in] Fontevraud 9-Contribution of Materials Investigations and Operating Experience to Light Water NPPs' Safety, Performance and Reliability, Avignon, 2018.

[32] M.K. Miller, K.A. Powers, R.K. Nanstad, and P. Efsing, Atom probe tomography characterizations of high nickel, low copper surveillance RPV welds irradiated to high fluences, $\mathrm{J}$. Nucl. Mater., 437(2013), No. 1-3, p. 107.

[33] Finnish Standards Association, ISO 148-1: 2016: Metallic Materials-Charpy Pendulum Impact Test - Part 1: Test Method, Standard, Finnish Standards Association, West Conshohocken, 2016.

[34] ASTM International, ASTM E185 -16: Standard Practice for Design of Surveillance Programs for Light-Water Moderated Nuclear Power Reactor Vessels, Standard, ASTM International, West Conshohocken, 2018.

[35] N. Hytönen, Effect of Microstructure on Brittle Fracture Initiation in a Reactor Pressure Vessel Weld Metal [Dissertation], University of Tampere, Tampere, 2019.

[36] S.J. Jones and H.K.D.H. Bhadeshia, Competitive formation of inter- and intragranularly nucleated ferrite, Metall. Mater. Trans. A, 28(1997), No. 10, p. 2005.

[37] T.L. Anderson, Fracture Mechanics Fundamentals and Applications, 2nd ed., CRC Press, Boca Raton, 1995.

[38] M. Kroon and J. Faleskog, Micromechanics of cleavage fracture initiation in ferritic steels by carbide cracking, J. Mech. Phys. Solids, 53(2005), No. 1, p. 171.

[39] L.F. Zhang, B. Radiguet, P. Todeschini, C. Domain, Y. Shen, and $\mathrm{P}$. Pareige, Investigation of solute segregation behaviour using a correlative EBSD/TKD/APT methodology in a 16MND5 weld, J. Nucl. Mater., 523(2019), p. 434. 